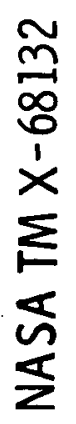

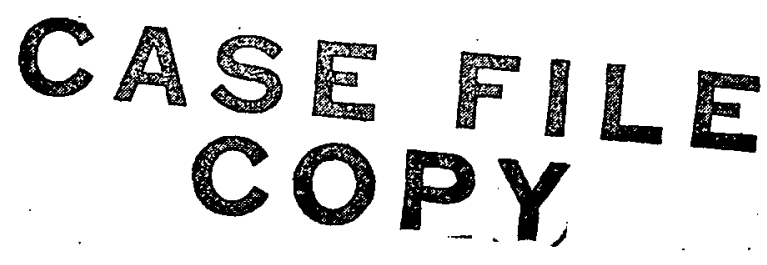

\title{
DURABILITY TESTS OF A FIVE-CENTIMETER DIAMETER ION THRUSTER SYSTEM
}

by Shigeo Nakanishi

Lewis Research Center

Cleveland, Ohio

TECHNICAL PAPER proposed for presentation at Eighth Propulsion Joint Specialists Conference sponsored jointly by the American Institute of Aeronautics and Astronautics and the Society of Automotive Engineers New Orleans, Louisiana, November 29-December 1, 1972 


\author{
Shigeo Nakianishi \\ National Aeronautics and Space Administration \\ Lewis Research Center \\ Cleveland, Oh1o
}

\section{Abstract}

A modified Hughes SIT-5 system is being tested for durability at the Lewis Research Center. As of October 1, 1972, the thruster subsystem has logged over 8000 hours of operation. The finttal 2023 hours were run with a translating screen thrust vector grid. The thruster is currently operating with an electrostatic type vector grid. Profiles and maps taken at widely separated intervals show that performance and operating characteristics have remained essentially constant. Overall efficiency is about 32 percent and power to thrust ratio is 170 watts per millipound at a specific impulse of 2500 seconds. Telescopic examination of the vector grid shows some sputtering erosion due to charge exchange and direct impingement ions. An independent test of the propeliant storage and cathodeisolator-vaporizer subsystem has demonstrated good reliability under simulated thruster operating conditions.

\section{Introduction}

The growling fnterest in long orbital life satellites for a variety of applications has increased the potential usefulness of electric thrusters for attitude control and stationkeeping. $(1,2,3)$ In particular, electrostatic ion thrusters are suitable for low thrust/high total impulse missions. The major propulsion system requirements for such missions are precistion, rellability, and lifetime. (4)

An ion thruster technology program for small mercury bombardment ion thrusters has been. in progress at the Lewis Research Center for several years. $(5,6)$ A $5-\mathrm{cm}$ diameter thrust vectorable structuraliy integrated ion thruster system was designed and developed by the Hughes Research Laboratories under Contracts NAS3-14129 and NAS3$14058 .(7,8)$ The Hughes SIT-5 thruster system has been tested to a limited extent within the scope of the contracts to evaluate performance and operatlonal charactéristics. $(9,10)$ To determine the ultimate life of the system and to pinpoint potential problem areas not discerntble in short-term tests; a program of durability testing has been undertaken at the Lewis Research Center.

This paper presents results of a continuing durability test on the Hughes SIT-5 thruster modifled for specific tests at Lewis.

Thruster operation (as of Oct. 1, 1972) exceeding 8000 hours 18 descrtbed. Compartsons are made with operating characteristica obtalned at

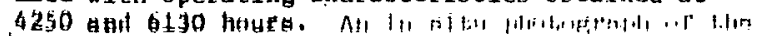
eleotfostatia vector erid 18 shown. An caliringed time history of the durability test to date is given. The results of the initial 2000 hours of testing performed with a translating sereen vector grid are also included. An independent test conducted concurrently on the STP-5 propeliant feed system is described.
Finally, an assessiment is made of the total testing program with a discussion of trends ind 1 cated by the tests thus far and possible problem areas for extended operation in space.

\section{Apparatus and Procedure}

\section{Hughes SIT-5 System}

An engtneering drawing of the first generation Hughes SIT-5 (Structurally Integrated Thruster, 5-cm diam.) as delivered is shown in flgure 1. Design details and performance of this system and of a second generation design are described in reference 7. A single gas pressurtzed propellant reservoir feeds mercury to the porous tungsten vaporizers of the main cathode and the neutralizer. A propellant isolator allows the feed system to operate at neutralizer potential. All the propellant to the dischane chamber is introduced through the main cathode which utilizes an enclosed keeper design. The cathode pole piece is vented to allow post-cathode diversion of the propellant into the discharge chamber. Permanent magnets provide the magnetic fleld. The figure shows a single grid ion extraction system. The durability test, however, was conducted with a translating screen vector grid(8) for the 1nitial 2000 hours. The test is being run presently with a two-axis deflection electrostatic vector grld which has a screen electrode having smaller holes at the center than at the edge. Performance characteristics of this type of grid is described in reference 8 . The neutralizer is also an enclosed keeper type. By proper sizing of the kecper hole, the neutralizer can operate at mercury flow rates as low as $1.5 \mathrm{~mA}$ equivalent $\mathrm{Hg}^{+}$.

\section{Thruster Test}

The SIT-5 system was modifled to meet speciftc requirements of the durability test. A photograph of the thruster fitted with an electrostaric vector grid is shown in figure 2. The propellant reservoir was removed and the vaporizers were connected to capillary flow tubes. The neutralizer was mounted on an isolated support and orlented to point downstream parallel to the thruster axis. The two boxes contain contaminant collectors for an adjunct experiment.

Figure 3 shows an interior view of the vert1cal vacuum tank before the test. The tank 18 $1.37 \mathrm{~m}$ in diameter and $1.83 \mathrm{~m}$ tali. A frozen mercury target was. used. The mercury was contalned in a stainless steel pan and cooled by radial copper atrute attached to the bottom of the pan to which

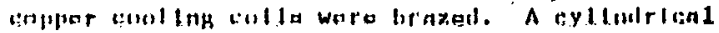
cooling coll brazed to vertical copper atrlps formed the cryowall which extended along the vertical wall of the tank. Liquid nitrogen was used for both the frozen mercury target and cryowall cooling.

The accelerator grid of the thruster was approximately $75 \mathrm{~cm}$ above the frozen mercury...target 
when installed. To prevent backsputtering of condensible conductive materlal upon the thruster, a set of nonmetallic (Fiberfax, 50 percent $\mathrm{Al}_{2} \mathrm{O}_{3}$, 50 percent $\mathrm{SiO}_{2}$ ) baffles were installed so that no metallic surface other than the mercury target in-

$\checkmark$ tercepted the line of sight of the thruster ion beam. With the target frozen and the cryowall at Iiquid nitrogen temperatures, the u1timate tank ipressure was generally in the mid-10-7 torr range. W1th the thruster operating, the pressure rose to about $1 \times 10^{-6}$ torr.

Provisions for taking in situ telescopic pictures of the accelerator grid were made by having a floodlight and a sputter shielded window mounted on the side of the vacuum facility. Details of the electrical system and test prodedures are described : in reference 11 . An automatic digital data acquisition systen obtained thruster data at clocked intervals. A protective control systen designed to shutdown the thruster in the event of abnormal thruster or test facility conditions allowed unattended operation around the clock. The thruster was operated open-looped at nominally fixed conditions except for minor day-to-day adjustments. Periodically, performance maps of thruster operating characteristics were obtained by varying a thruster parameter while holding all other var1ables constant. The ion chamber and neutralizer propellant flow rates were held at about $34 \mathrm{~mA}$ and $2.2 \mathrm{~mA}$, respectively, throughout the test.

\section{Propellant Feed System Test}

Because the propellant reservolr was separated from the SIT-5 system for the thruster durability test, it was desirable to perform an independent durability test of the propellant reservolr including an identical cathode, isolator, and vaporizer assembly. A schematic drawing of the propellant feed system test installation in a vacuum bell jar is shown in figure 4. An electrical wiring schematic is included in the drawing. The propellant reservoir was mounted on electrically isolated supports and floated from ground. A voltage clamping circult normally used in thruster test was incorporated. A simulated thruster shell without magnets was mounted on the CIV (cathode-isolatorvaporizer) assembly. The discharge current or emission current normally drawn to the thruster anode was drawn to a simulated anode connected to the cathode via a discharge power supply. The positive high voltage was applied to the simulated anode, as in a thruster, to provide a realistic test of the 1solator.

It was necessary to enclose the entire assembly except the discharge end of the simulated thruster shel1 with a grounded screen. This enclosure eliminated stray fon currents which gave erroneous readings of low microampere level current through the isolator leakage detection circult.

Throughout the test, the cathode keeper cur- rent was maintained between 0.25 and $0.30 \mathrm{~A}$. Disblhatep curpent waz hell at: $0.30-10.40 \mathrm{~A}$. Rolh of thege ourrenit levels are typlcal of tliruater operation. Propellant flow rate was held constant by matntalning the vaporizer temperature as hear as possible to $340 \pm 2^{\circ} \mathrm{C}$ with minor day-to-day adjustments of a fixed output power supply. Perlodic imeasurement of the pressure transducer resistance - was made with a Rubicon potentiometer. Operating,

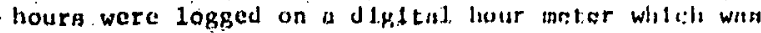

wired to stop when the positfve high voltage to the anode tripped out due to a breakdown overcurrent or bell jar over-pressure condition.

\section{Results and Discussion}

This section will first present the latest thruster performance profile after 8022 hours into the test compared with two earlier points. An abridged time history from the start of test will show beam outage events and any long term varlation in several thruster parameters. Thruster operating characteristics at widely separated points in the test w111 be compared. In situ photographs of the thrust vector grid in test will be shown and grid operating characteristics will be examined. F1 nally a brief resume of the propellant feed system test will be made to show its reliability.

\section{Performance Profile}

A performance profile of the thruster taken at the time of writing is shown in Table I compared with others taken earlier in the test. The third column shows values obtained with a translating screen vector grid near the end of that test. The design beam current maintained throughout the test was $25 \mathrm{~mA}$. Beam power was higher when the electrostatic vector grid was used because of the higher net accelerating potential required for proper optics characteristics. Discharge power was higher because of lower screen electrode transparency, 2.3. 8 percent compured wi.th 4.16 percont in the translating screen grid. Component power requirements were essentially constant throughout the test except for a slight increase in the neutra11zer keeper power.

Propellant utilization efficiency varled slightly because of the difficulty in setting the propellant flow rate at exactly the same value at all times. Power and hence overall efficiency and thrust tended to be higher at the higher specific impulse used with the electrostatic vector crid. Similarly. power to thrust rutio wis also higher because power increases directly with net accelerating potential whereas thrust increases as the square root of net accelerating potentiul.

\section{Time History of Test}

The thruster durability test was essentlally a steady-state test at fixed operating conditions. The thruster parameters held constant throughout the test are shown in Table $I I$ and wili not be $\bar{p} \bar{I} \bar{E}-$ sented in the time history. The cathode vaporizer temperature was adfusted to obtain the required beam current with the ion chamber discharge current held constant at nominally 0.4 and $0.26 \mathrm{~A}$ for the electrostatic and translating grids, respectively. The discharge voltage was very sensitive to cathode propellant flow, increasing with decreasing flow rate. Adjustment to the nominal value of $32-34 \mathrm{~mA}$ equivalent flow rate malntained the discharge voltage between 37 and 40 volts.

The cathode keeper current was varied from 0.25 to $0.35 \mathrm{~A}$ at different periods in the test for exploratory purposes. For most of the test, however, the keeper discharge was currentcontrolled at $0.30 \mathrm{~A}$.

Inolator lenkape current was monttored only clurlup the firut 2000 houra of the teut when tho 
translating screen optics were operated at 1000 volts. No leakage current was detectable on a 20 microampere full scale meter which indicated that the current was always less than 0.1 microampere. The SIT-5 isolator was contractually designed for 1000 volts. At the start of the electrostatic vector grid portion of the test, sufficlent data from the propeliant feed system test was not avallable to risk operation at 1300 volts. The vaporizer end of the CIV was, therefore, floated after the 2000 hour point.

The neutralizer flow rate was held between 2 to $2.3 \mathrm{~mA}$ equivalent throughout. Neutralizer keeper current ranging from 0.3 to $0.45 \mathrm{~A}$ was tried: during the early portion of the test. From the 1000 hour point on, the neutralizer keeper discharge was current-controlled at $0.45 \mathrm{~A}$.

An abridged time history of the test is shown in figure 5. Because of the highly compressed scale, fine detalls cannot be shown here. Details of the first 2000 hours of test with the translating screen grid are reported in reference 11 .

In addition to the four parameters charted, various beam outage events are marked. Three neutralizer outages occurred in the early hours of the test. These were attributed to high current surges from the output filter capacitors of the high voltage power supplies during grid arcs. Addition of suitable series inductive ballasts alleviated this condition. Later neutralizer outages were due to a vector grid arc at 2650 hours and a low temperature excursion of the neutralizer vaporizer at 4125 hours.

Four complete shutdowns of the thruster occurred because of tank pressure rising above $5 \times 10^{-5}$ torr. These conditions were test facility generated and would not occur in space flight. Three beam outages were caused by one or more transistors failing in the current control section of the discharge power supply. Protective diodes and clipcells have been Installed, but occasional failure still occurs. Thus far, three temporary grid shorts have occurred. They are temporary in that sustained application of sufficient current cleared the short (possibly a flake of sputtered metal) to permit continuation of the test. Thruster shutdown during a short is caused by a protective circuit which guards against high accelerator drain current.

Durfing sormal thruster operation, the accelerator drain current was less than one-half percent of the beam current as shown in figure.5(a). As w111 be shown later, the optics were operating in a region where drain current is not particularly sensitive to applied voltages. Not lceable increases in drain current could be observed with increase in propcllant flow rate. This indicates that most of the observed drain current was due to charge exchange 1ons.

The cathode keeper voltage shown in $\mathrm{fig}_{\mathrm{g}}$ ure $5(b)$ exhibited a rise in the early part of the test, but remalned at essentially a constant value thereafter unt1 the end of the tranolating grid test. Exposure to atmouphere whiflo inutalitng the electzostatia vector grid apparently did not degrade cathode operation. Restart after exposure presented no problem. One thousand hours after the exposure, the keeper voltage actually decreased and at the time of this writing is operating at 12 volts. Except for the starting periods, the cathode has been operated with no heater power.

The neutralizer keeper voltage and the thruster floating potential (figs. $5(\mathrm{c}$ ) and (d)) are somewhat inter-related and w111 be examined jointly. The thruster floating potential is strongly influenced by electron emission from the neutralizer. Neutralizer outage precludes thruster operation because of highly negative thruster floating potential. The long-term rise in neutralizer keeper voltage was accompanied by a simllar rise in floating potential. The neutralizer was operated with 3 watts of heater power which seemed to permit more stable neutralizer operation than with no heater power. Addition of up to 10 watts of heater power lowered the keeper voltage and floating potential as shown at 6500 and agaln at 7000 hours of operation. It is belleved that some minimum cathode temperature is necessary to preserve the low work function surface which enhances electron emission.

\section{Thruster Operating Characteristics}

Data obtained with the electrostatic vector grid configuration are presented in this section. The test hours indicate the total hours of operation on all thruster components except the vector grid which was installed at 2023 hours. Actual grid hours thus equal the test hours minus 2023.

Cathode keeper current. The ef fects of varying the cathode keeper current while holding all other parameters at nominal conditions are shown in figure 6. Figure 6(a) shows that the volt-ampere characteristics of the cathode were identical at 4250 and 6130 hours. The time history given in figure 5 shows that at 4250 hours the keeper voltage had already been near its stabilized value for about 1000 hours. The volt-amp curve had a positive slope at the nominal operating point of $0.3 \mathrm{~A}$ with a reversal at a keeper current of $0.35 \mathrm{~A}$. The ion chamber discharge current and voltage shown in: figures $6(\mathrm{~b})$ and (c) also underwent trend reversals: at keeper currents greater than $0.3 \mathrm{~A}$. An alternate varlation of changing the cathode keeper current without adjusting the ion chamber discharge showed the beam current to peak at or near a keeper current of $0.3 \mathrm{~A}$. The spread in data of the discharge parameters is belleved to be due to slight differences in propellant flow rates. Other data. shown in later figures tend to support this explanation.

Discharge current. The effects of varying the ion chamber discharge current while holding the cathode keeper current at $0.3 \mathrm{~A}$ is shown in $\mathrm{fig}$ ure 7 . The beam current (f1g. $T(a)$ ) showed similar trends at both points in the test. The 4250 hour data were slightly above the later data lndicating slightly h1gher propellant flow. Th1s 1s consiotent with the trends in accelerator drain current and discharge voltage shown in f1gures $7(b)$ and (c) As noted earlier, drain currents increase with charge exchange ion production, and discharge voltage decreases with increased propellant flow.

Noutrnllzer kceper current. The effects of varying neutralizer kecper current 18 ahown in figure 8. Two sets of data were taken at the 6130 hour point with tip heater powers maintalned at the normal 3 watts and also at zero. With minor dif -... 
ferences, the keeper voltage ( $f 1 \bar{g} \cdot 8(\mathrm{a})$ ) and thruster floating potential (fig. 8(b)) exhibfted similar trends at both points in the test. Reducing tip heater power tended to raise the keeper ivoltage and floating potential. A set of data points was taken at 7100 hours with the tip heater power Increased to 10 watts. As shown earlier in the time history (fig. S(c) and (d)), both the keeper voltage and the thruster floating potential decreased. In all cases, the thruster floating potentfal rose steeply as keeper current was reduced. A keeper current of 0.45 A appears to be sufficient for most conditions thus far in the test.

Operating maps such as those shown here are taken at discrete points in the test. They refiect: propellant flow rate or possibly neutralizer operating conditions at a particular time. As the time history has shown, there were minor ups and downs in the neutralizer related parameters is well as gradual long-term effects. In durability testing, the long-term effects bear watching, especlally if they are unidirectional. The neutralizer characteristics that appear to possess such long-term trends are the keeper voltage and the thruster floating potential.

\section{Thrust Vectoring Subsyster}

Two types of thrust vectoring grids have. been used in the durability test. The translating grids has been reported extensively in references 8 and 10. In the present test, after 2023 hours, grid erosion was minimal, giving an extrapolated ife of over 20 000 hours. (12) The discussion w111, therefore, be confined to the electrostatic vector grid because of its many hours of continued testing.

Since the start of the electrostatic vector test at 2023 thruster hours, the grid has not been exposed to the atmosphere. In situ examinations with a telescope have been made at periodic intervals. To assist in the interpretation of the highly magnified photo, a cutaway section of the electrostatic vector grid is shown in figure 9. Each beamlet hole is surrounded by accelerator grid elements on four sides. The grid elements are 0.5 thick and 2.5 wide and notched at the intersection to avoid electrical contact. The intersection region is covered by a bent tab attached to one of the grid elements. These tabs protect the grid elements from charge exchange lons which focus into the intersections. Because of the oblique sighting angle, the grid elements will appear as a stack of plates and the beamlet holes will not be visible in the photograph.

A photograph of a grid region approximately 1.6 by $1.8 \mathrm{~cm}$ is shown in figure 10 . This photo was taken after. 4000 hours of 8 r1d operat1on. Note the charge exchange plts forming on the protective tab over the intersectlons. The Inside surfaces of ithe grid elements show some curved sputter erosion "patterns. It Is believed that these are caused by ;ilghly divergent lons emanating from a clrcular beam hole to form a conle acction where they interrect the grid element plane.

The vector grid has been operated in the beam deflection mode for a total of 2000 hours to date In four directions. About 120 hours have been at a maximum deflection of 5 degrees based on a deflec- : tion voltage of 250 volts. The remainlng houra have been at deflection angles of 2 to 4 degrees.

Grid shorting noted in the time history has occurred between grid elements as well as between the screen and accelerator electrodes. Thus far, these shorts have been cleared by a sustained application of 200-400 volts at currents ranging from 6 to $70 \mathrm{~mA}$. These shorts are belleved to be caused by accumulation of sputtered metal which build up in the incersections then peel off. Interelectrode shorts between the screen and accelerator may also be caused by bulldup of sputtered metal or sputtered metal flakes shed from ion chamber surfaces.

Net accelerating potential variation. The effects of varying the net accelerating potential with the beam current held at $25 \mathrm{~mA}$ are shown $1 \mathrm{n}$ figure 11. These varlations were made at 4100 hours of grid operation. The accelerator potential was held at -900 volts. The accelerator drain current (fig. 11(a)) decreased slightly as the net accelerating potential was increased beyond the nominal 1300 volt operating value.

The Ion chamber discharge current and voltage (figs. 11(b) and (c)) were essentlally constant. A slight decrease in discharge current was observed, indicating better ion extraction at the higher potentials.

Accelerator potential. The effects of varying the accelerator potential while holding net accelerating potential at 1300 volts and the beam current at $25 \mathrm{~mA}$ is shown in figure 12 . The drain current (fig. 12(a)) showed a slightly rlsing trend with increasing accelerator potential. This trend may be due to increasing beam divergence which is characteristic of high accelerator potentials.

The discharge current and voltage (fig. 12(b) and (c)) both increased slightly with decreasing accelerator potential. This trend is consistent with reduced ion extraction effects seen carlier when net accelerating potential was varied.

\section{Propellant Feed System Test}

The propellant reservoli and CIV assembly which were separated from the SIT-5 thruster system were tested independently in a vacuum bell jar. The purpose of the test was to evaluate the following factors:

1. Long-term retention capabilicy of the propellant reservoir pressurizing gas.

2. Vaporizer flow control over a long operatIng period.

3. Propellant feed 1solator durability under simulated thruster operation.

\section{Cathode durability.}

By the nature of the test, a.11 four factors were evaluated concurrently over the test duration of 5400 houre. Tho vaporizer was operated at a conatant tamperature of $340^{\circ} \mathrm{C}$, and 1300 volts was impresed acrose the 1solator.

A plot of the transducer resistance which 18 proportional to gas pressure 18 shown in $\mathrm{ftg}_{\mathrm{g}}$ ure $13(\mathrm{a})$ as a function of .test time... On.July 14,... 
1971 , a bench reading was made at room temperature. The reading was adjusted to $40^{\circ} \mathrm{C}$, the operating reservo1r temperature, and plotted at time zero. Subsequent transducer readings were made at $40^{\circ} \mathrm{C}$ and plotted directly. Feed system installation was completed, and the test was actually begun on September 30,1971 . The 5400 hours of operation was not obtained unt1l June 20, 1972 because of vacuum facility fallures and repair shutdowns which occurred in the interim. A simplified analysis given in Append Ix A shows the relationship between the time rate of change in the gas pressure and the ivolume change which occurs because of propellant outflow under isothermal conditions. The prope1lant reservolr was found to attain a constant stabilized temperature of about $40^{\circ} \mathrm{C}$. Assuming that the propellant flow rate is constant, the volume change should be linear with time.

Based on the analysis, the ratio of the $1 \mathrm{ni-}$ tial transducer resistance to the resistance at a specific test time is plotted in figure $13(\mathrm{~b})$. This method of analysis is convenient in that the value of Initfal resistance does not change the slope of the line drawn through the data points. The time rate of change of the resistance ratio equals the time rate of change of the volume ratio, $V / V_{i}$ where $V=$ gas volume at time $t$, and $v_{i}=$ initial gas volume. The initial gas volume was measured by filling a gas reservolr of identical design with water.

The significant result of the feed system test. is that the volume change of the gas, and hence the displacement of mercury propellant was linear. with time. It can thus be concluded that the flow rate was constant over the test period and that the gas reservoir does not leak if the calculated flow rate is of the right magnitude. As shown in Appendix A, the flow rate of $30.4 \mathrm{~mA}$ calculated from the pressure data agree favorably with those obtained by other means 1ncluding mass measurements. In the thruster durability test, the same operating temperature on a vaporizer of identical design is yielding a propellant flow of $33-34 \mathrm{~mA}$.

The isolator was tested primarily at 1300 volts with the cathode operating at conditions representative of thruster operation. Several exploratory periods of operation at 1350 volts across the isolator were tried. The leakage current showed no increase at the higher voltage. Within 1 to 4 hours of unattended operation, however, the power supply over-current breaker, would trip, indicating that a breakdown had occurred. No breakdowns occurred at 1300 volts. The leakage current throughout the test remained at less than 0.1 microampere.

The evaluation of cathode durability in this test was not a rigorous in-thruster evaluation because of the differences in the configuration and the discharge plasma. Nthough cathode discharge currents and voltages were representative of thruster conditlons, the plasma environment and Ion bombardment of cathode surfaces were probably also different in the test. The confining nature of the enclosed keeper destgn, however, may shield the cathode sufficiently even in a thruster discharge chamber so that cathode life is prolonged.

Vlaual tagpection after 5400 hours showed no

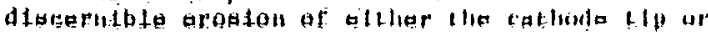
the keeper aperture. All components of the CIV assembly were in functional order, but the test was terminated to make way for a second generation CIV assembly designed to operate at 1600 volts.

\section{Concluding Remarks}

Continuing durablity tests of a structurally integrated $5-\mathrm{cm}$ diameter ion thruster system are being conducted at the Lew1s Research Center. The Hughes SIT-5 thruster modified for specific tests is operating at over 8000 hours at the time of this writing.

A time history of the test and performance mapping at widely separated intervals have shown that the cathode, ion chamber discharge, and accelerator draln current characteristics have remained essentially constant throughout the test. The neutralizer keeper voltage and the thruster floating potential have shown a slight rise with time. This may be indicative of a gradual degradation of the enissive surfaces within the neutralizer cathode. Several methods of eifminating or minimizing the degradation process are being investigated in other tests.

A translating screen thrust vector grid showed minimal erosion after 2023 hours. In situ examination of the electrostatic thrust vector grid in current use has shown some eroston due to charge exchange and possibly direct 1mpingement ions. Grid shorting is a potential problem. Methods of clearing these shorts are also being investigated.

An independent test of the SIT-5 propellant feed system conducted for 5400 hours has demonstrated its reliability. The test was terminated to make way for a second generation cathodeisolator-vaporizer assembly designed to operate with 1600 volts across the 1solator. Results to date at 2100 hours are encouraging.

Al1 tests thus far have been at steady-state operation except for startups following an occasional shutdown. Restarts have been reliable and easy even after $7: 100$ hour: application to a particular mission may require duty cycle operation. Rellability testing under an on-off cyclic mode has been successfully performed to a limited extent by Hughes Research Laboratories as part of a contract effort. Extended reliability testing will be performed at the Lewis Research Center.

\section{Appendix A}

Calculation of Propellant Flow Rate from Gas Pressure Measurements

The time variation of the pressure transducer ohmic resistance is shown in figure 13. Because the ineasured pressure is linear with the transducer resistance, the equation for pressure 18

$$
\text { P - KR }
$$

where

P gas pressure

$k$ caldbration conatant

R. transducer resiotanco 
Assuming 1sothermal expansion of the confined gas volume, the equation of state is

$$
P V=C=P_{i} V_{1}
$$

where

$P_{1} \quad$ Initial gas pressure

$v_{1}$ initial gas volume

iv gas volume at any time, $t$

or

$$
\frac{V}{v_{1}}=\frac{p_{1}}{p}
$$

The time derivatives are:

$$
\begin{aligned}
\frac{d}{d t}\left(\frac{v}{V_{i}}\right) & =\frac{d}{d t}\left(\frac{P_{i}}{P}\right) \\
& =\frac{d}{d t}\left(\frac{K R_{i}}{K R}\right)=\frac{d}{d t}\left(\frac{R_{i}}{R}\right)
\end{aligned}
$$

At initial conditions when the reservolr was loaded, the inftial resistance was

$$
R_{1}=3500 \Omega
$$

and the initial volume was

$$
v_{1}=538 \mathrm{cc} \text { (measured volume) }
$$

A plot of the quantity $R_{i} / R$ is shown as a function of time in figure 13(b). The slope of the line through the points gives a value for

$$
\begin{gathered}
\frac{d}{d t}\left(\frac{v}{V_{i}}\right)=3.15 \times 10^{-5} 1 / \mathrm{hr} \\
\frac{d V}{d t}=3.15 \times 10^{-5} \times 538=1.69 \times 10^{-2} \mathrm{cc} / \mathrm{hr}
\end{gathered}
$$

Because the time rate of change of the volume of the pressurizing gas equals the change of the mercury propellant volume, assuming mercury density of $13.5 \mathrm{gm} / \mathrm{cc}$ at $40^{\circ} \mathrm{C}$,

$$
\dot{\mathrm{m}}=228 \mathrm{mg} / \mathrm{hr}
$$

This corresponds to an $\mathrm{Hg}^{+}$equivalent flow rate of $30.4 \mathrm{~mA}$. Average flow rate calculated from system mass measurements was $32 \mathrm{~mA}$. . Inferred flow characteristics of this and stmilar vaporizers reported in reference 9 were about $30 \mathrm{~mA}$ at comparable vaporizer temperatures.

\section{Refercices}

1. Pree, B: A., and Huson, G., "Selected Compar1sons Among Propulaton Systems for Commicat1ons Satell1tes," Paper 72-517, Apr. 1972. ALA , New York, N.Y.

2. Payne, W. F., Bens, A. R., Bassett, D. A., and Lovell, R. R., "Cholce of an Ion Englne for the Comunications Technology Satellite," Paper 72-491, Apr. 1972, AIAA, New York, N.Y.
3. Free, B. A., "Economic Tradeoff Studies for Electric Propulston Missions on Communications Satellites," Paper 71-683, June 1971, AIAA, New York, N.Y.

4. Hawk, C., Baty, R., Rosen, S., and Qu1rk, J., "System Study of Electric Propulsion for Military Space Vehicles," Paper 72-493, Apr. 1972, AIAA, New York, N.Y.

5. Nakanisht, S., Lathem, W. C., Banks, B. A., and Weigand, A. J., "Status of a Five-CentimeterDiameter Ion Thruster Technology Program," Paper 71-690, June 1971, ALAA, New York, N.Y.

6. Reader, P. D., Nakanishi, S., Lathem, W. C., and Banks, B. A., "A Submililpound Mercury Electron Bombardment Thruster," Journal of Spacecraft and Rockets, Vol. 7, No. 11, Nov. 1970, pp. 1287-1292.

7. Hyman; J., Jr., "SIT-5 System Development," Paper 72-492, Apr. 1972, AIAA, New York, N.Y.

8. Collett, C. R., King, H. J., and Schnelker, D. E., "Vectoring of the Beam from Ion Bombardment Thrusters," Paper 71-691, June 1971, AIAA, New York, N.Y.

9. Hyman, J., Jr., "Design and Development of a Small Structurally Integrated Ion Thruster System," NASA CR-120821, Oct. 1971, Hughes Research Labs., Malibu, Calif.

10. King, H. J., Collett, C. R., and Schnelker, D. C., "Thrust Vectoring Systems. Part I: 5-cm Systems," NASA CR-72877; 1970, Hughes Research Labs., Malibu, Calif.

11. Nakanishi, S., and Finke, R. C., "A 2000-Hour Durability Test of a Five-Centimeter-

\begin{tabular}{|c|c|c|c|}
\hline urs & & 4250 & 2023 \\
\hline Vector grid type & $\begin{array}{l}\text { Electro- } \\
\text { static }\end{array}$ & $\begin{array}{r}\text { Electro- } \\
\text { static }\end{array}$ & Trans- \\
\hline Optics transparency, $\%$ & 28.8 & & 45.6 \\
\hline $\begin{array}{l}\text { Net accelerating } \\
\text { potential, V }\end{array}$ & 1300 & 1300 & 1000 \\
\hline Beam power, $W$ & 32.5 & 32 & 25 \\
\hline Discharge power, $W$ & 15.1 & 13.8 & 9.4 \\
\hline Component power & & & \\
\hline $\begin{array}{l}\text { Accelerator draln, W } \\
\text { Cathode, W } \\
\text { Neutralizer, } W\end{array}$ & $\begin{array}{r}.2 \\
9.0 \\
12.8\end{array}$ & $\begin{array}{r}0.2 \\
9.9 \\
12.5\end{array}$ & $\begin{array}{r}0.14 \\
9.7 \\
11.6\end{array}$ \\
\hline$\ldots \ldots$ & & & \\
\hline $\begin{array}{l}\text { Total input power, } W \\
\text { Power efficlency, } \bar{x}\end{array}$ & $\begin{array}{l}09.6 \\
46.6\end{array}$ & $\begin{array}{l}68.9 \\
47.2\end{array}$ & $\begin{array}{r}55.84 \\
44.9\end{array}$ \\
\hline Utilization efficiency, & & & \\
\hline$x$ & 70.5 & 69.0 & 69.6 \\
\hline Overall efficlency, $\bar{z}$ & 32.8 & 32.6 & 31.3 \\
\hline $\begin{array}{l}\text { Thrust, mlb } \\
\text { Spec1fic impulse, sec }\end{array}$ & $\begin{array}{r}.41 \\
2540 \\
170\end{array}$ & $\begin{array}{l}0.41 \\
2480\end{array}$ & $\begin{array}{l}0.36 \\
2200 \\
-155\end{array}$ \\
\hline
\end{tabular}
Diameter Mercury Bombardment Ion Thruster," Proposed NASA Technical Memorandum.

12. Lathem, W. C., "Grid-Translation Beam Deflection Systems for $5-\mathrm{cm}$ and $30-\mathrm{cm}$ D1ameter Kaufman Thrusters," Paper 72-485; Apr. 1972, AIAA, New York, N.Y.

Table I - Performance profile 


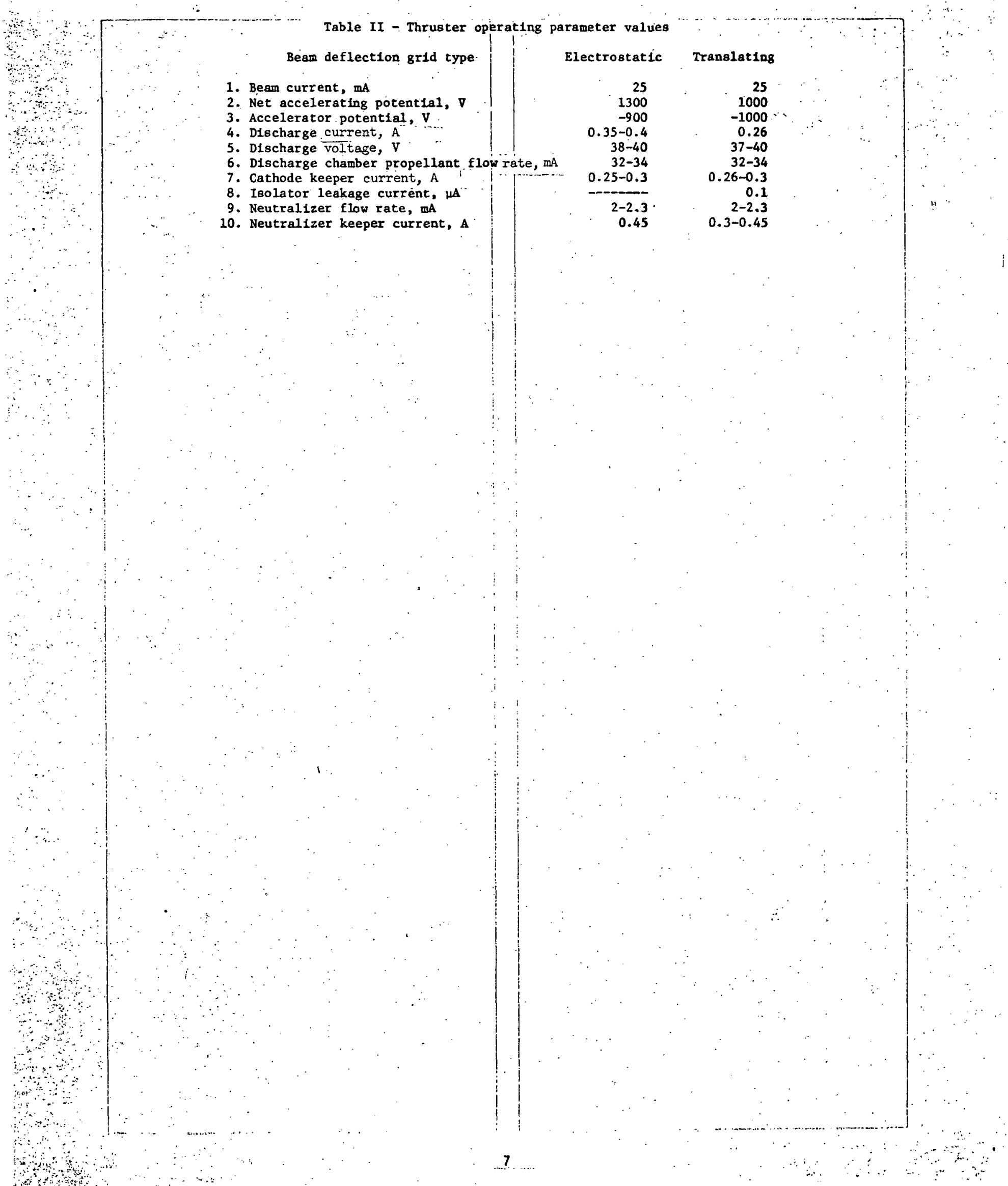




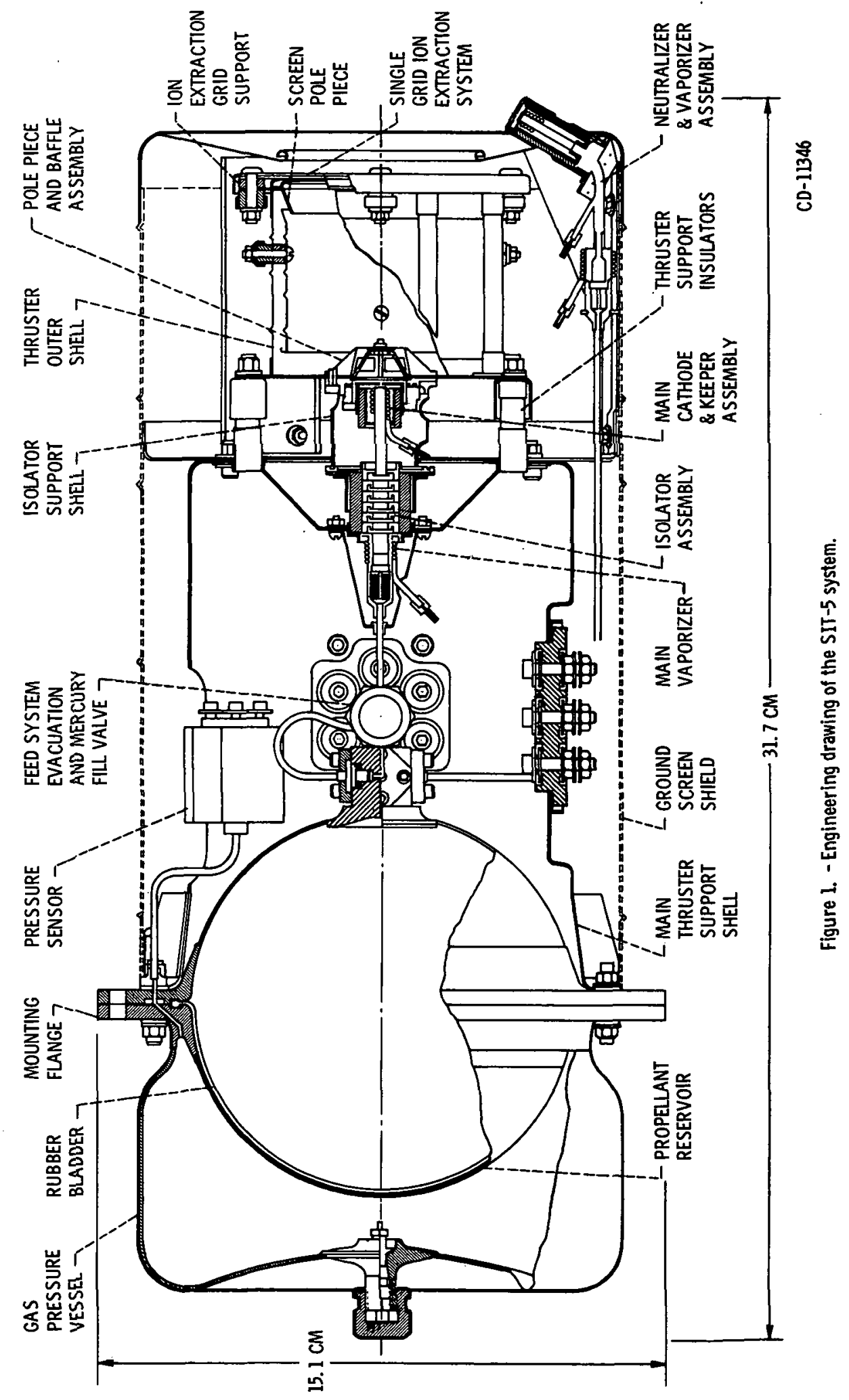




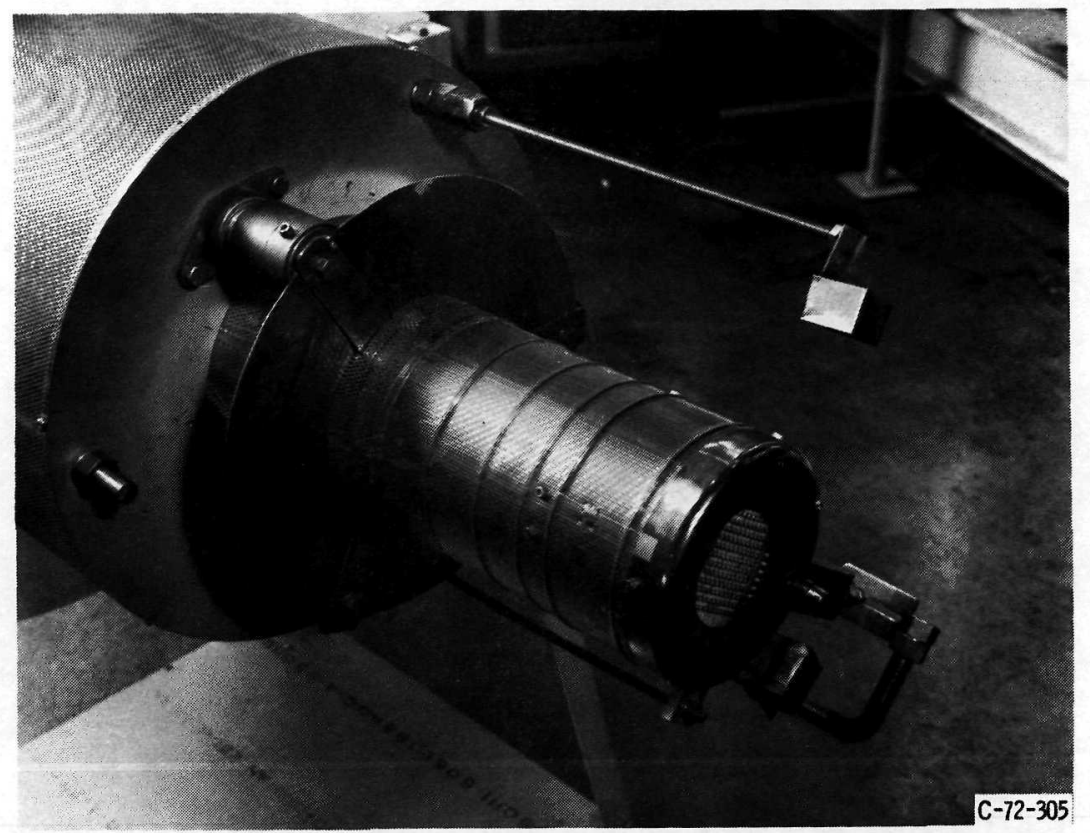

Figure 2. - Test installation of modified SIT-5 thruster.

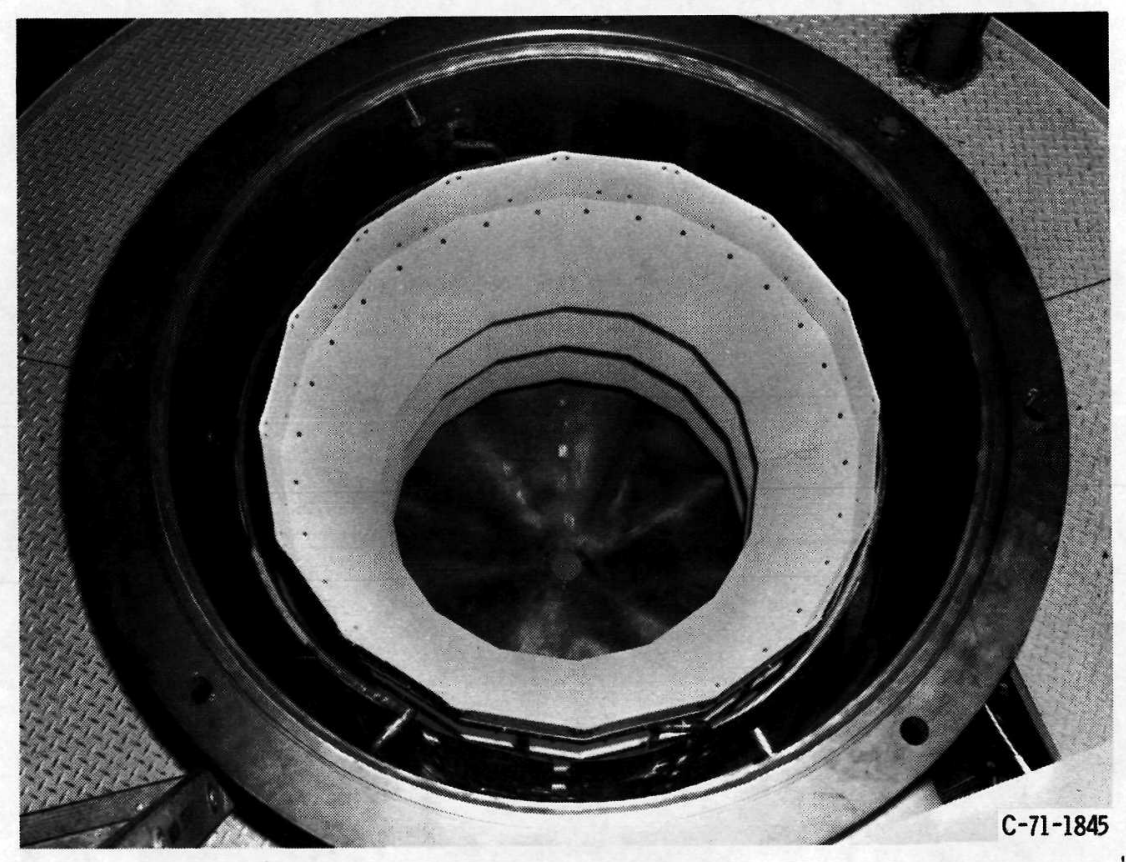

Figure 3. - Tank interior before test. 


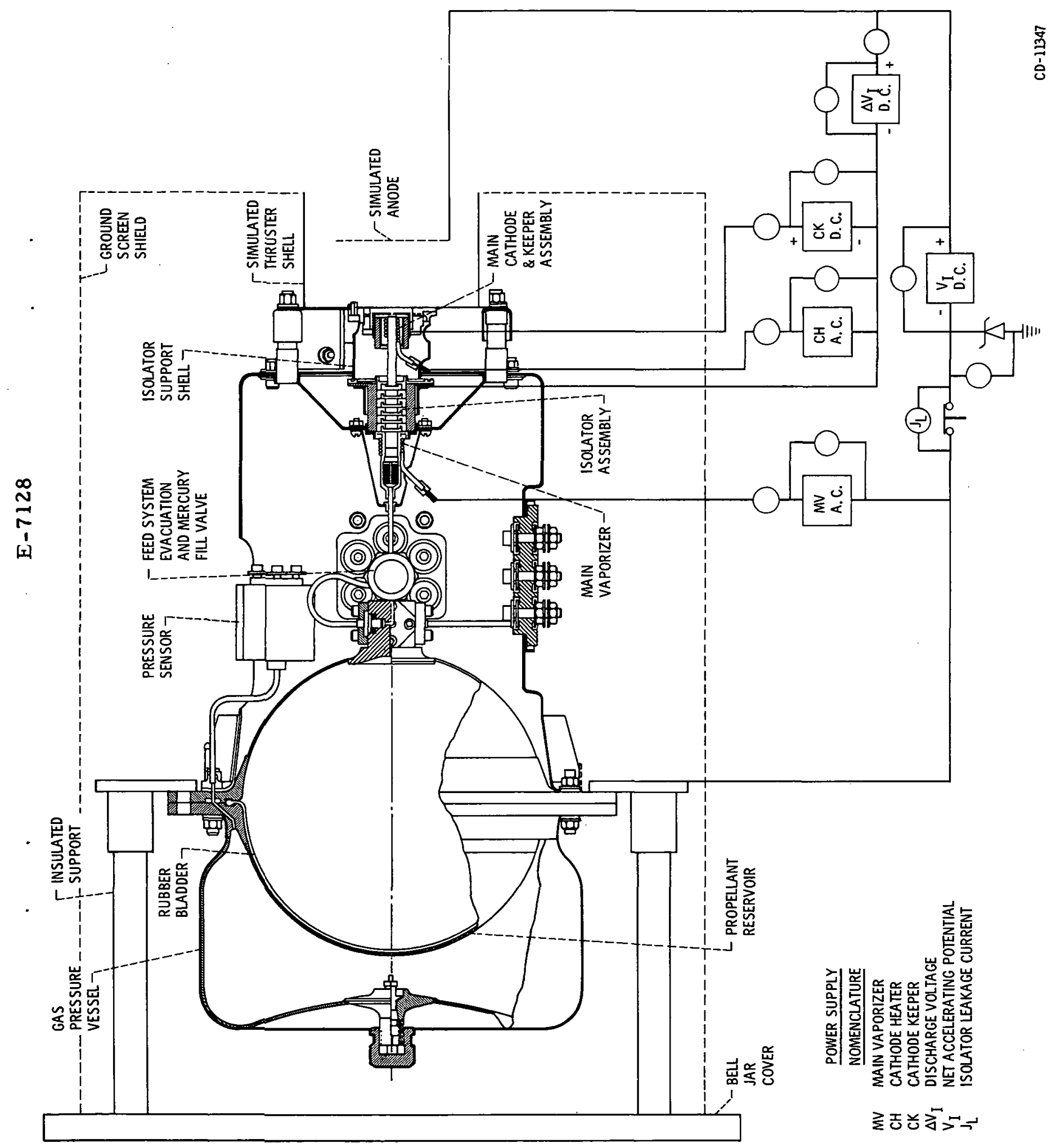

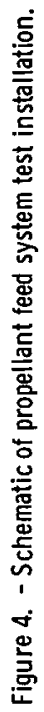



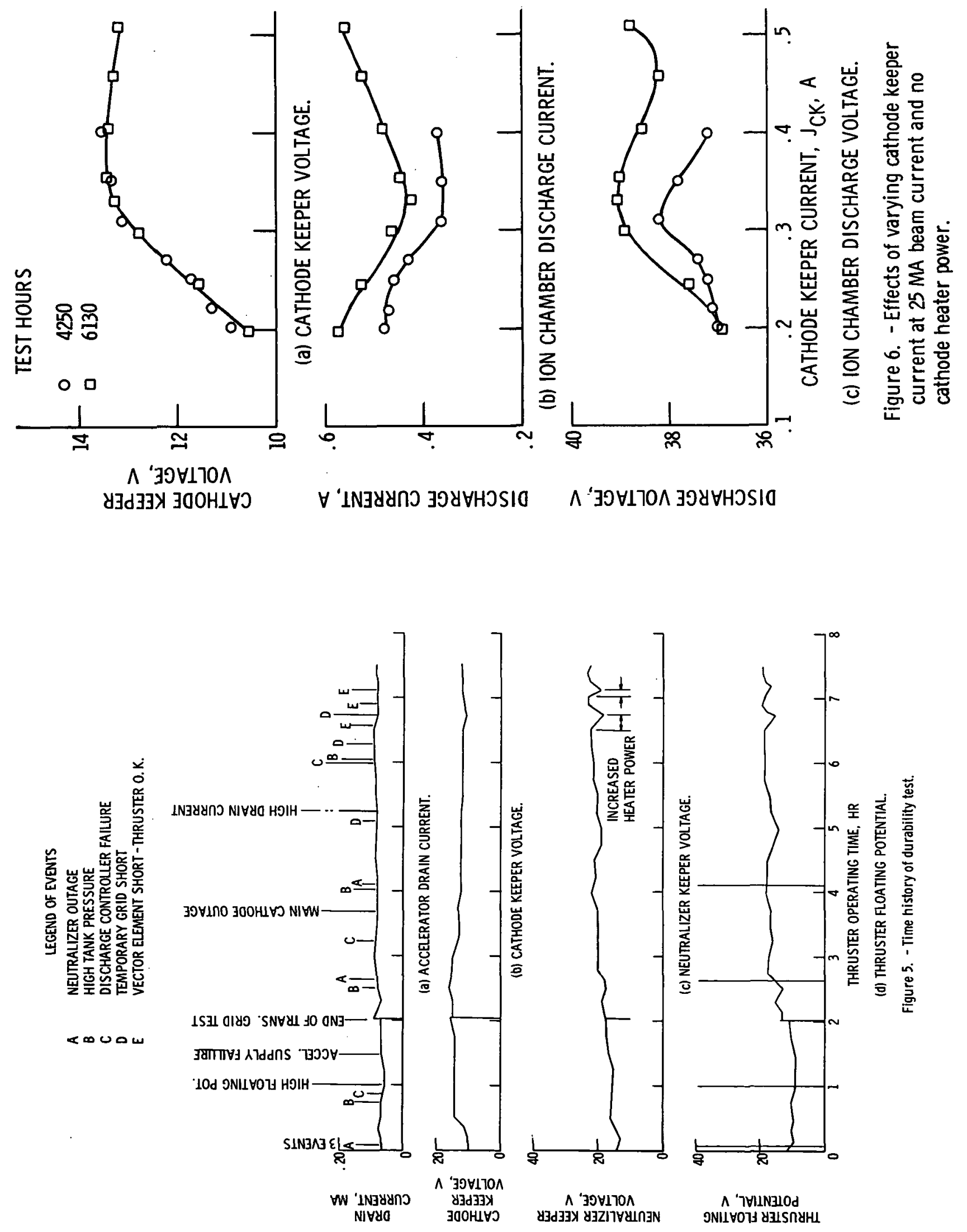


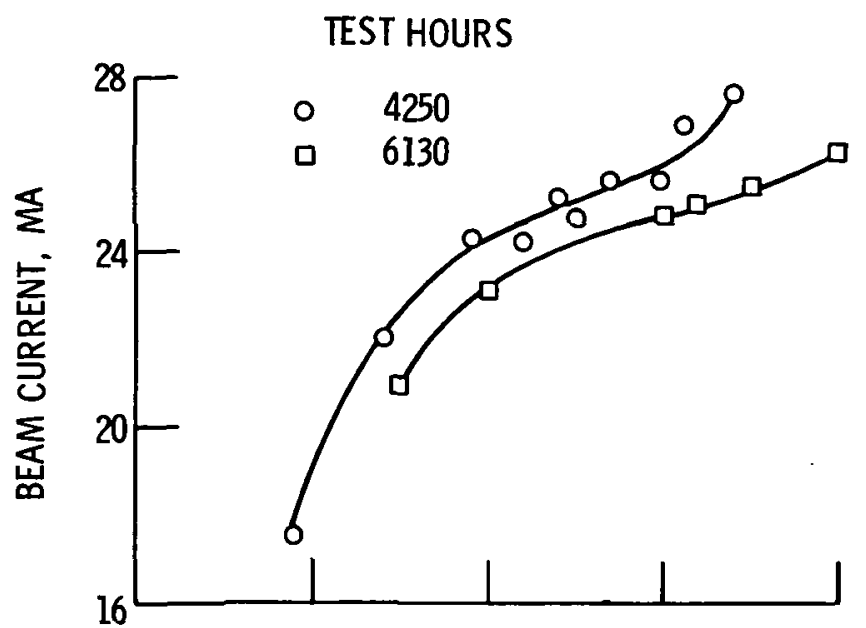

(a) BEAM CURRENT.

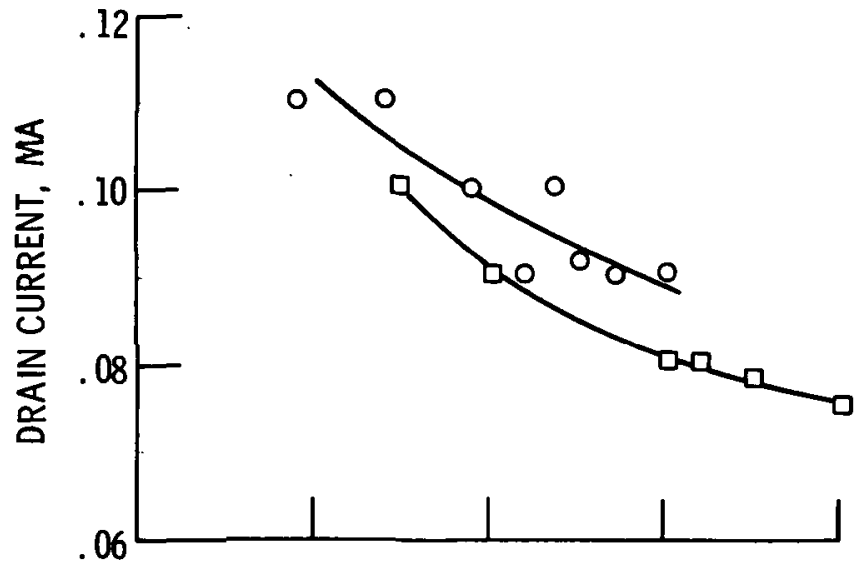

(b) ACCELERATOR DRAIN CURRENT.

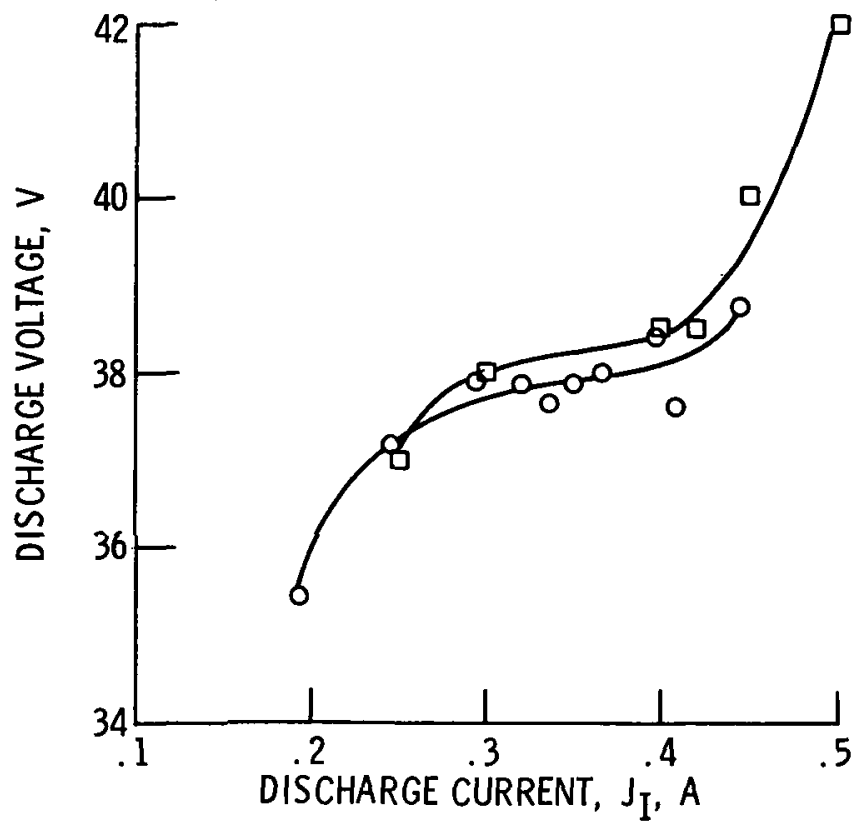

(c) ION CHAMBER DISCHARGE VOLTAGE.

Figure 7. - Effects of varying discharge current at $0.3 \mathrm{~A}$ cathode keeper current and no cathode heater power. 


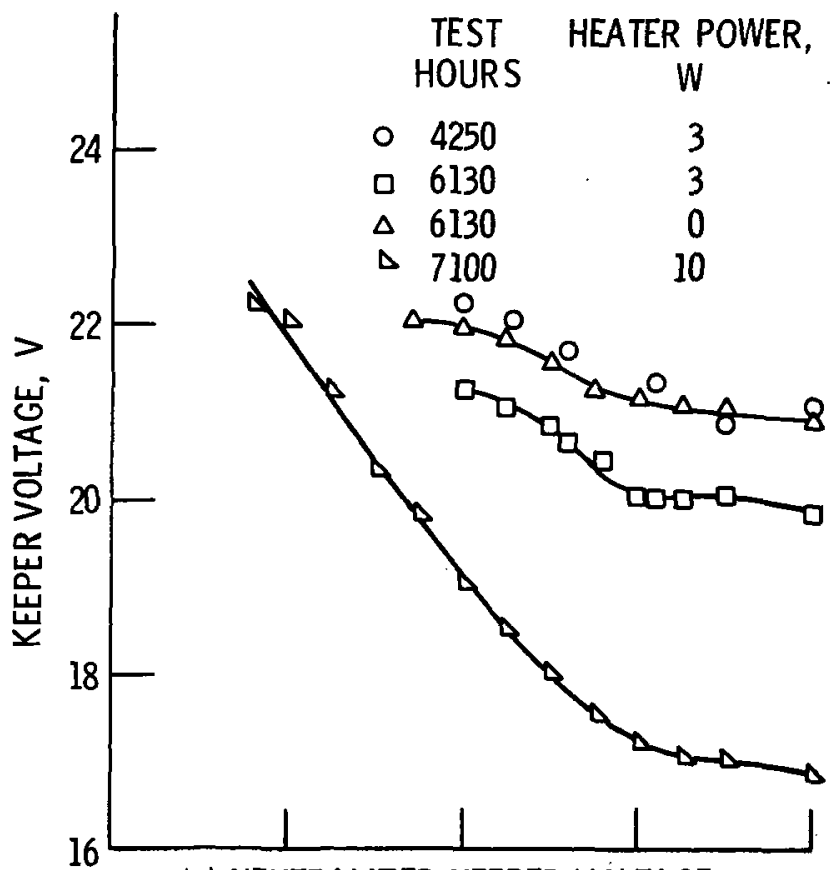

(a) NEUTRALIZER KEEPER VOLTAGE.

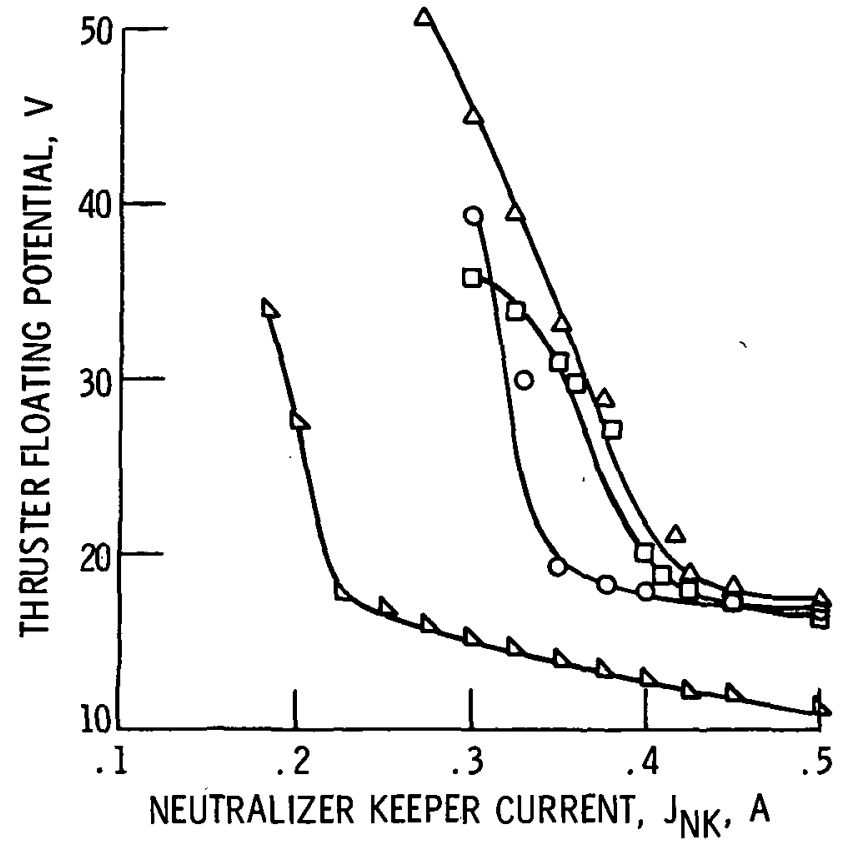

(b) THRUSTER FLOATING POTENTIAL.

Figure 8. - Effects of varying neutralizer keeper current. Beam current, $25 \mathrm{MA}$. 


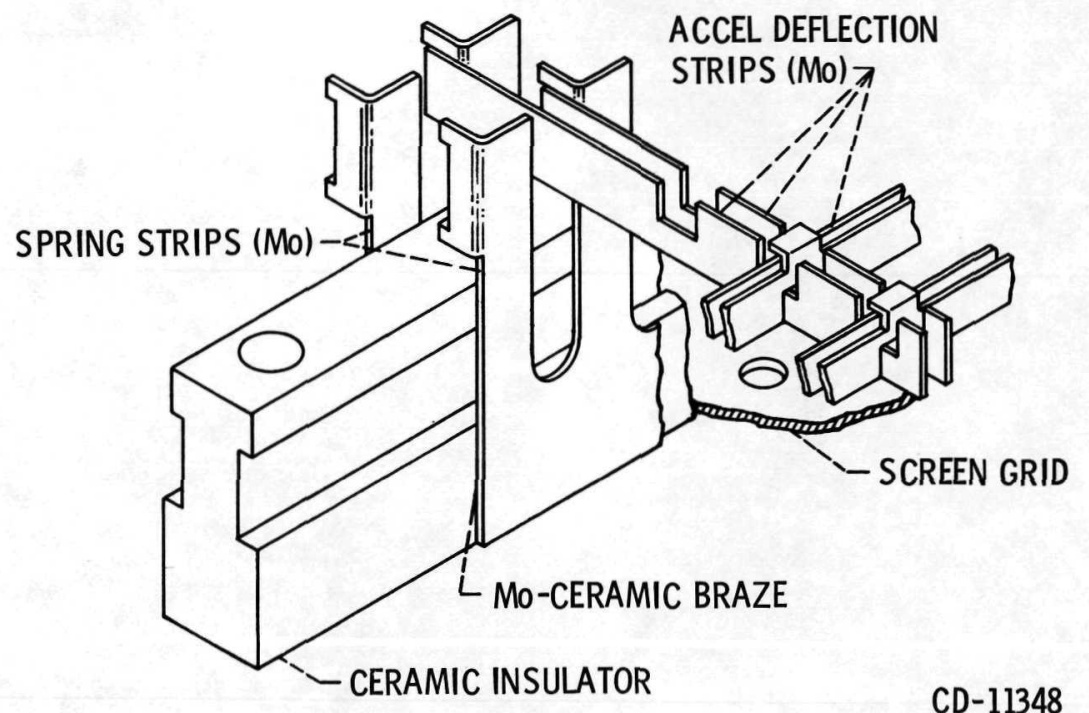

Figure 9. - Cutaway view of electrostatic vector grid assembly.

龒

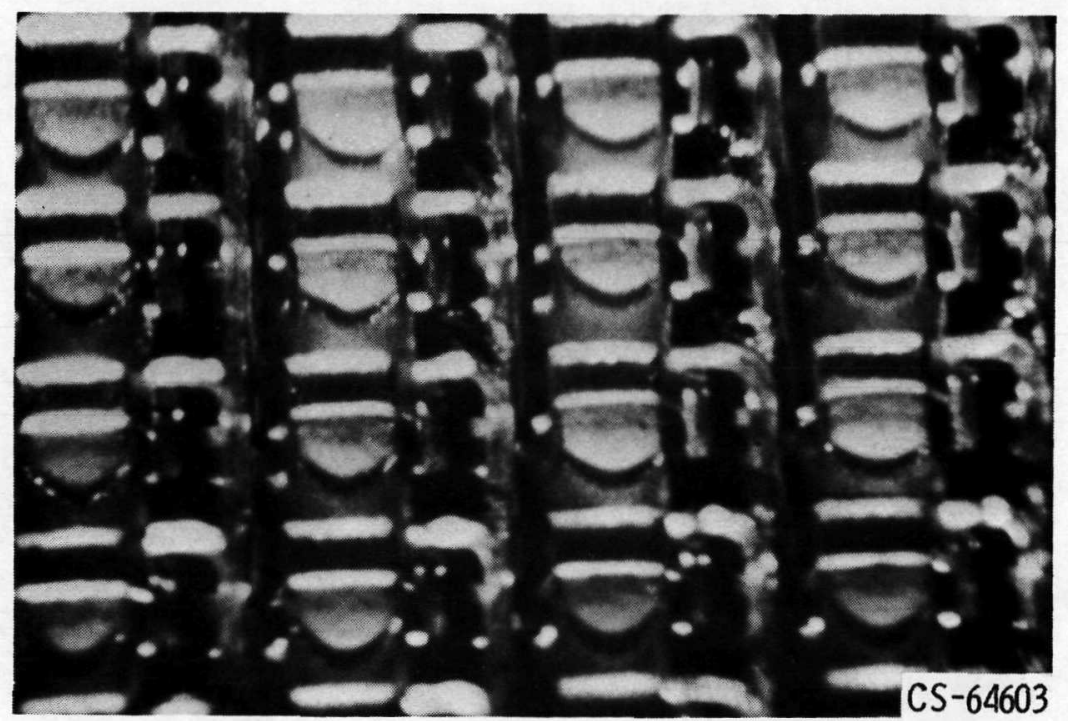

Figure 10. - Electrostatic vector grids in operation at 4000 hours. 

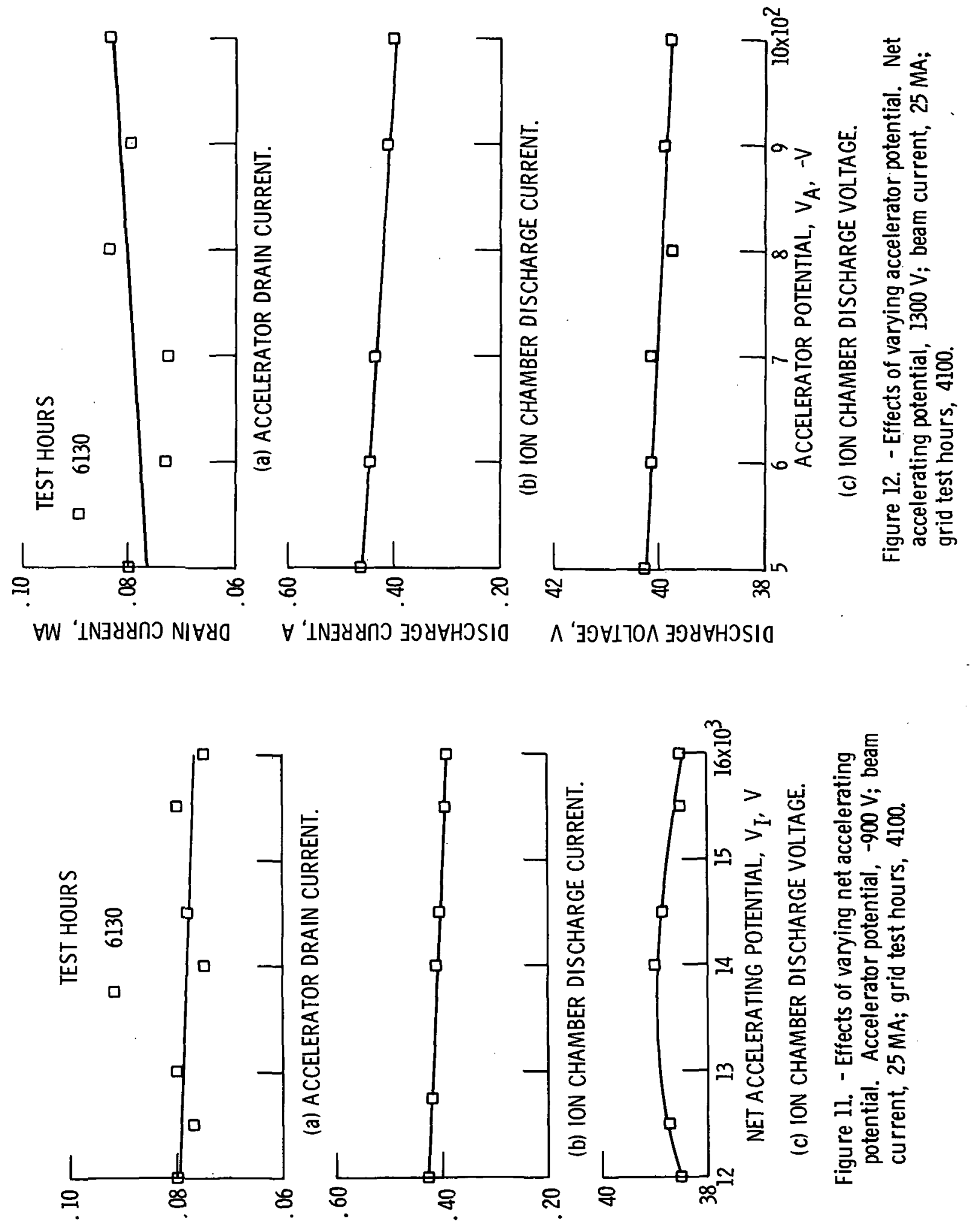

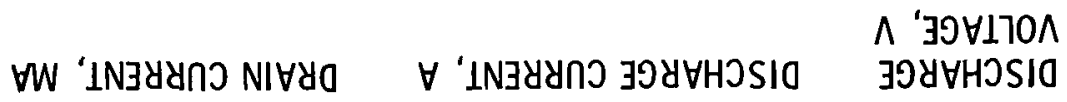




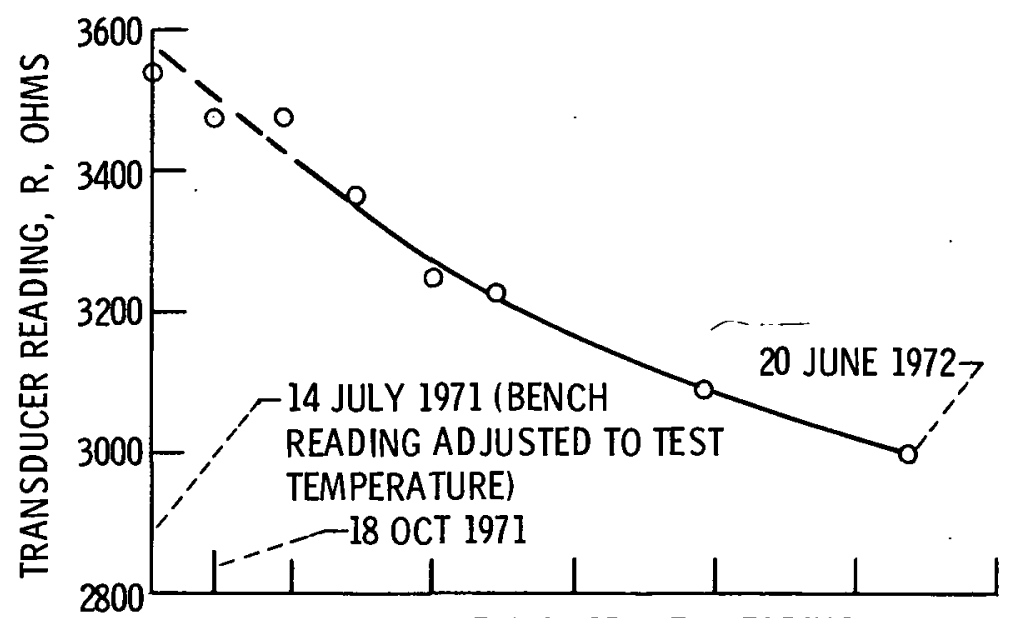

(a) PRESSURE TRANSDUCER READING.

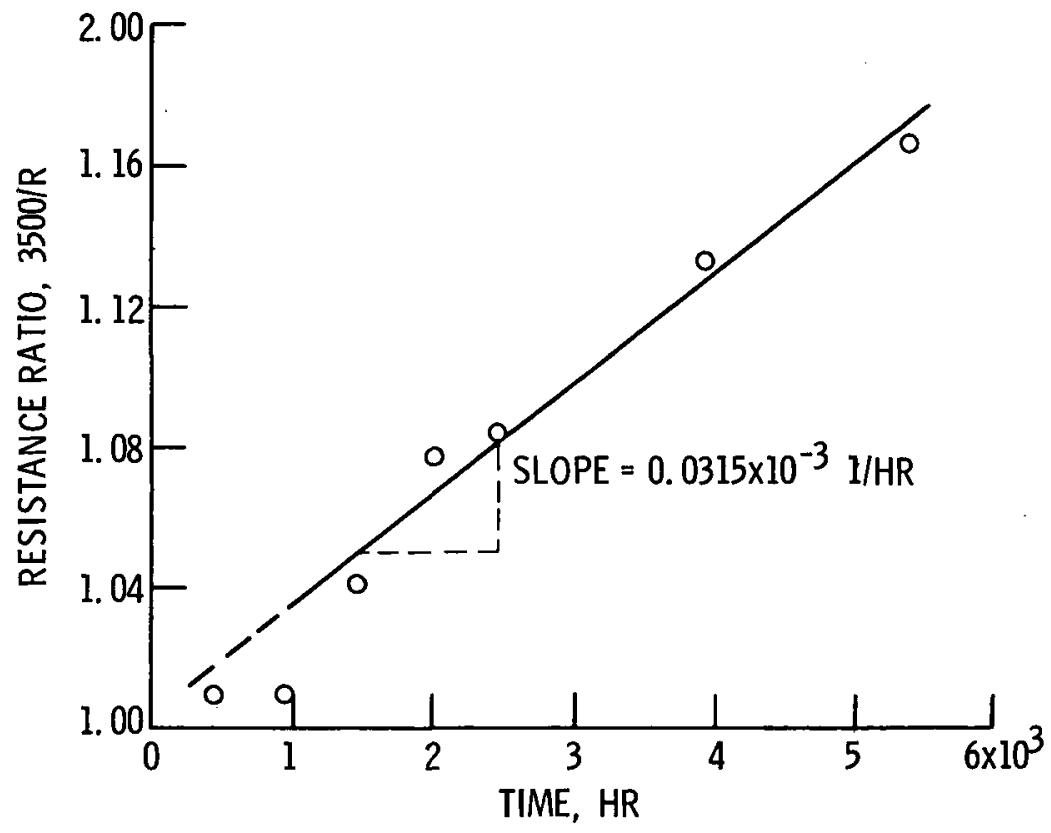

(b) RATIO OF INITIAL TO TEST RESISTANCE.

Figure 13. - Time history of propellant reservoir test. 